\title{
Woody twigs as a microhabitat for myxomycetes in the upland forests of southwestern Virginia
}

\author{
Cedeño $\mathbf{M}^{1}$, Clayton $\mathrm{M}^{2}$ and Stephenson $\mathrm{SL}^{2}$ \\ ${ }^{1}$ Bella Vista, Calle 42, Edificio Rocamar, Apart. 9B, Panama City, Panama \\ ${ }^{2}$ Department of Biological Sciences, University of Arkansas, Fayetteville, Arkansas 72701
}

Cedeño M, Clayton M, Stephenson SL 2014 - Woody twigs as a microhabitat for myxomycetes in the upland forests of southwestern Virginia. Mycosphere 5(5), 673-680, Doi $10.5943 /$ mycosphere $/ 5 / 5 / 8$

\begin{abstract}
The moist chamber culture technique was used to investigate the assemblages of myxomycetes associated with woody twigs in five different types of upland forest communities in the Mountain Lake area of southwestern Virginia. The myxomycetes of these same five forest communities had been studied intensively during the period of 1982-1986, but at that time woody twigs had not been recognized as a distinct microhabitat for this group of microorganisms. In the present study, samples of woody twigs collected in June 2013 were used to prepare a series of 60 moist chamber cultures. Fifty-nine of the 60 cultures $(98 \%)$ yielded fruiting bodies of myxomycetes, and 23 species in 10 genera were recorded from 148 specimens. Arcyria cinerea was the single most common species and represented 35\% of all records. Only nine other species were recorded from $\geq 5$ cultures, and nine species were represented by only a single record.
\end{abstract}

Key words - ecology - moist chamber cultures - Mountain Lake - slime molds

\section{Introduction}

The myxomycetes (also referred to as myxogastrids or plasmodial slime molds) are a group of fungus-like organisms that have been known from their fruiting bodies since at least the mid17th century (Martin \& Alexopoulos 1969, Stephenson 2011). Approximately 900 species are known (Lado 2005-2014), and some of these apparently occur anywhere on earth where there are plants and thus plant detritus. Myxomycetes are often common in nature, where their fruiting bodies are found associated with such microhabitats as decaying coarse woody debris (Stephenson \& Stempen 1994). However, the occurrence of fruiting bodies is sporadic and the fruiting bodies themselves relatively small and thus often difficult to detect in the field. As such, the moist chamber culture technique as it applies to myxomycetes (Gilbert \& Martin 1933) provides a convenient and often very productive method of supplementing field collections when studying these organisms (Stephenson 1989).

In temperate deciduous forests, myxomycetes are known to occur on the dead leaves that make up a major portion of the litter layer that occurs on the forest floor (Härkönen 1981, Stephenson 1988, Stephenson \& Stempen 1994, Tran et al. 2008, Rollins \& Stephenson 2012). Except in those exceptional instances in which a forest is dominated by a single tree species, the litter layer is relatively heterogeneous, consisting of an often complex mixture of dead leaves derived primarily from a number of different species of trees and other woody plants. In addition to 
dead leaves, the litter layer also contains other types of plant material, including small pieces of dead bark, woody twigs and various plant-derived reproductive structures (e.g., seeds, fruits, inflorescences and cones). In most situations, woody twigs are the most abundant non-leaf components of the litter layer. Stephenson et al. (2008), who studied the myxomycetes associated with twigs collected from 12 localities located in several different regions of the world, found that the assemblages of species they recorded were not the same as those associated with dead leaves. They suggested that woody twigs represent a distinct microhabitat for myxomycetes in forest ecosystems.

During the period of 1982-1986, the third author carried out an intensive ecological study of the myxomycetes associated with five different types of upland forest communities in the Mountain Lake area $\left(37^{\circ} 22^{\prime} \mathrm{N}, 80^{\circ} 37^{\prime}\right.$ W) of southwestern Virginia (Stephenson 1988). Braun (1950) included the Mountain Lake area within the Ridge and Valley Section of the Oak-Chestnut Forest Region. The major trees present are various species of oak, with chestnut oak (Quercus prinus L.) and northern red oak (Q. rubra L.) the most important. American chestnut (Castanea dentata [Marsh.] Borkh.), formerly a dominant or codominant species in these forest communities, was almost completely eliminated by the chestnut blight during the first half of the $20^{\text {th }}$ century (Stephenson 1986). Throughout the area, mixed mesophytic communities with beech (Fagus grandifolia Ehrhart) present and sometimes dominant occur in sheltered ravines and coves, and spruce (Picea rubens Sarg.)-hemlock (Tsuga canadensis [L.] Carr) communities occupy a few of the most mesic high-elevation sites. Other species of trees present in the general study area include red maple (Acer rubrum L.), sugar maple (A. saccharum Marsh.), black birch (Betula lenta L.), shadbush (Amelanchier arborea [Michaux f.] Fernald) and several species of hickory (Carya spp.).

At the time this earlier study was carried out, woody twigs had not been recognized as a distinct microhabitat for myxomycetes. Moreover, twigs of sufficient size to be easily noticed were selectively removed from the samples of litter collected for the preparation of moist chamber cultures. As such, the purpose of the present study was to supplement the data obtained during the period of 1982-1986 by examining the assemblages of myxomycetes associated specifically with woody twigs and then comparing the taxonomic composition of these assemblages with those obtained previously for the leaf litter microhabitat.

\section{Materials \& Methods}

Samples of woody twigs (defined herein as woody stems $\leq 1.0 \mathrm{~cm}$ in diameter) were collected from the same five study areas used in the previous study (Table 1). Individual twigs (Fig. 1) were collected randomly along a line transect extending through each study area. Enough twigs were collected in a particular study area to fill five small paper bags. The latter were transported to the Eumycetozoan Laboratory at the University of Arkansas, where the twigs were used to prepare a series of 12 moist chamber cultures for each forest type, for a total of 60 cultures for the entire study. The culture chambers used consisted of $15 \mathrm{~cm}$ plastic disposable Petri dishes, each lined with a piece of filter paper. Enough sample material was placed in the Petri dish to cover the bottom as completely as possible yet still allowing a lid to be placed securely on the dish. Distilled water was then added to each Petri dish and the latter left undisturbed for a period of approximately 24 hours, when the $\mathrm{pH}$ of what had become a moist chamber culture was determined with a portable $\mathrm{pH}$ meter and a flat surface electrode. After the value of $\mathrm{pH}$ had been recorded, most of the water in each Petri dish was poured off, and the moist chamber cultures stacked and placed in an area of the laboratory receiving only diffuse light. Each culture was examined once a week for a period of several months, and water was added when necessary to maintain moist conditions. When fruiting bodies of myxomycetes appeared in a culture, a portion of the twig (or twigs) upon which they occurred was removed, glued to a small paper tray, and the latter mounted in a pasteboard box for permanent storage. All occurrences of the same species in a single moist chamber culture were considered to represent one record. Identifications were made with the use of standard monographs. Nomenclature used herein essentially follows Lado (2005-2014) except for Stemonitis nigrescens, 
where the treatment used is that of Martin \& Alexopoulos (1969). Voucher specimens of all species are deposited in the herbarium of the University of Arkansas (UARK).

Table 1 Summary data on the five different types of forest communities from which samples of woody twigs were collected in the present study.

\begin{tabular}{|c|c|c|c|}
\hline Study area & $\begin{array}{l}\text { Elevation } \\
\text { (m) }\end{array}$ & Topographic position & Forest community type \\
\hline Beanfield Mountain & 1115 & Open S-facing slope & Oak-hickory \\
\hline Spruce Bog & 1130 & $\mathrm{~N}$-facing slope of a shallow ravine & Red spruce-hemlock \\
\hline War Spur & 1135 & Open, S-facing slope & Mixed oak-red maple \\
\hline Pond Drain & 1170 & Protected, E-facing slope & $\begin{array}{l}\text { Mixed mesophytic (beech } \\
\text { the primary dominant) }\end{array}$ \\
\hline Bald Knob & 1243 & Open, N-facing slope & Red oak \\
\hline
\end{tabular}

The sets of data obtained for the different study areas were compared using coefficient of community (also known as the Sorensen index) and percentage similarity indices (MuellerDombois \& Ellenberg 1974, Gauch 1982). The equation for the former, which is based solely on a consideration of the presence or absence of species, is coefficient of community $(C C)=2 c /(a+b)$ where $a$ is the total number of species in the first community (or assemblage) being considered, $b$ is the total number of species in the second community, and $c$ is the number of species shared in common. The value of $\mathrm{CC}$ ranges from 0 (when no species are present in both communities) to 1.0 when all species are present in both communities.

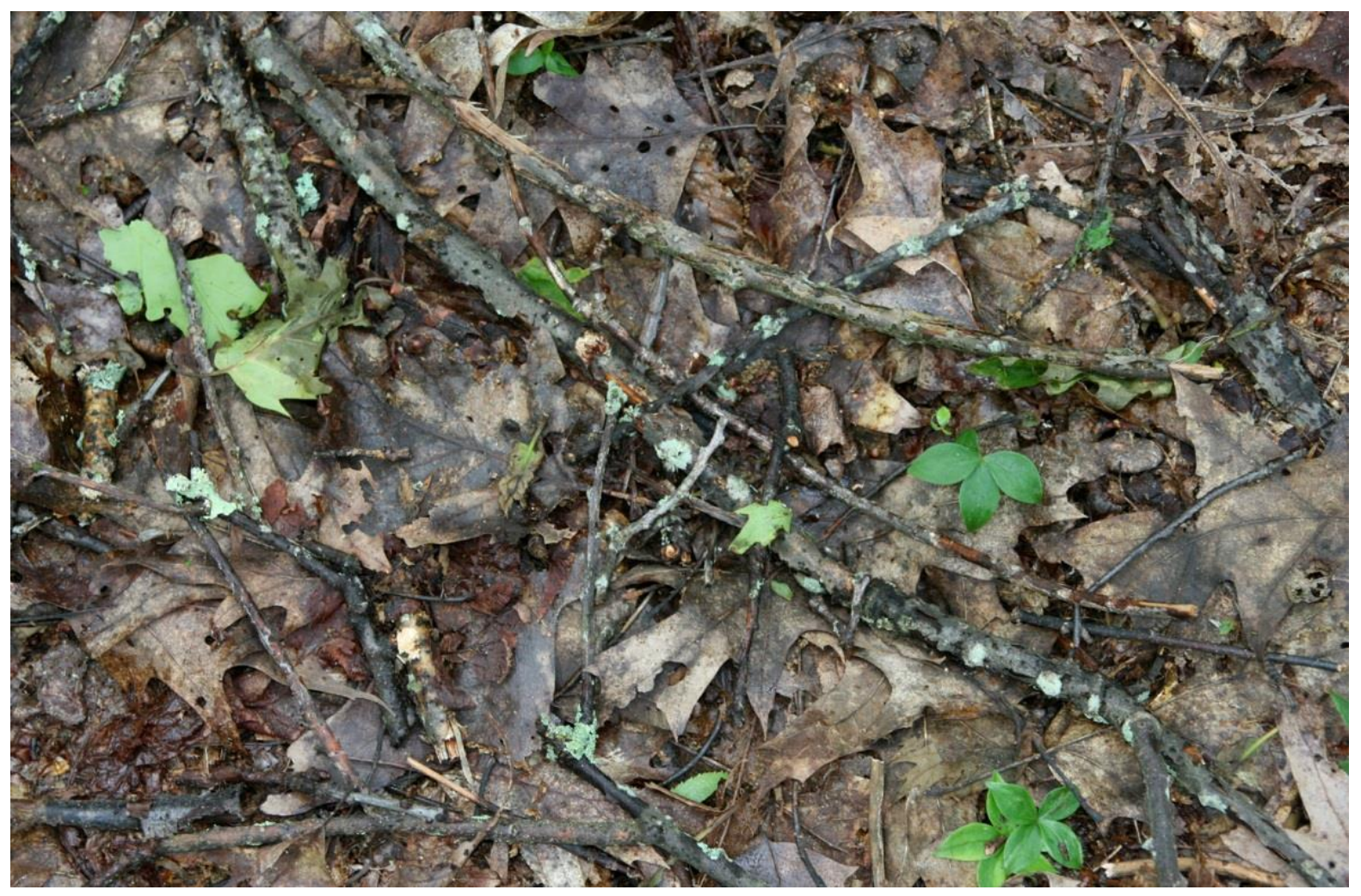

Fig. 1 - Woody twigs on the forest floor of one of the five study areas in the Mountain Lake area of southwestern Virginia. 
The equation for percentage similarity, which considers the relative abundance of species in a community and not just their presence, is percentage similarity (PS) $=\Sigma \min (\mathrm{a}, \mathrm{b}, \ldots \mathrm{x})$ where min is the lesser of the two percentage composition values of species $a, b, \ldots . x$ in the two communities. The value of PS ranges from 0 for communities with no species in common to 1.0 for communities identical both in species composition and quantitative values for the species. In addition, species diversity indices were calculated for the sets of data using the Shannon-Weaver index of diversity (Shannon \& Weaver 1963), which is species diversity $\left(\mathrm{H}^{\prime}\right)=-\Sigma$ Pi log Pi where $P i$ is the proportion of the total number of individuals represented by species $i$. This index varies from a value of 0 for a community containing a single species to some maximum value for a community containing many species, each represented by a small number of individuals.

To evaluate the completeness of the survey, a series of rarefaction curves was constructed using the records obtained from the moist chamber cultures for each study area. Species accumulation curves were generated using the Chao 2 estimator obtained with the software program EstimateS as recommended by Unterseher et al. (2008). The data obtained were later adjusted according to the formula $y=a x /(b+x)$ as suggested by Raaijmakers (1987). This approach allows a visual examination of the completeness of the survey and provides a comparative figure for the alpha-diversity among study areas.

\section{Results}

Fifty-nine of the 60 moist chamber cultures (98\%) yielded the fruiting bodies of myxomycetes, and 23 species in 10 genera were recorded from 148 specimens (Table 2). Several of the specimens were represented by poor or limited material and could be identified only to genus (e.g., Comatricha sp. A and Physarum sp. A), but in each instance the species involved was clearly different from any other member of the same genus recorded in the present study. The number of species recorded for a particular study area varied from only seven for Bald Knob to 15 for Beanfield Mountain. Numbers of records followed the same pattern, with Bald Knob characterized by the lowest total (17 records) and Beanfield Mountain (37 records) one of the two study areas (Spruce Bog was the other one) with the highest total. Arcyria cinerea was the single most abundant species and represented $35 \%$ of all records. It was the only species recorded from all five study areas. Eleven of the 23 species were recorded from only a single study area, and only nine species (Comatricha nigra, Diderma effusum, Echinostelium minutum, Licea operculata, Perichaena chrysosperma, Physarum oblatum, Physarum viride, Stemonitis flavogenita, Stemonitis nigrescens) other than $A$. cinerea were represented by at least five records.

Values of $\mathrm{pH}$ recorded for all 60 moist chamber cultures ranged from 3.6 to 7.1, with a mean of 4.9. Cultures prepared with twigs from Spruce Bog were the most acidic (mean $=4.2$, range $=3.6$ to 4.9 ), whereas those from Beanfield Mountain (mean $=6.3$, range $=4.4$ to 7.1 ) were the least acidic. Mean values for the other study areas were 4.6 (War Spur), 4.9 (Pond Drain) and 5.0 (Bald Knob). Beanfield Mountain also had the highest species richness (15) for myxomycetes, which might suggest some correlation of species richness and $\mathrm{pH}$. However, Spruce Bog, which had the most acidic twigs, was characterized by the second highest species richness.

Although the data are limited, it is interesting to note that the study area (Beanfield Mountain) at the lowest elevation was characterized by the highest species richness (15 species), whereas the study area at the highest elevation (Bald Knob) was characterized by the lowest species richness (only 7 species).

The five study areas were compared using coefficient of community and percentage similarity indices (Table 3). The average value for all possible combinations of study areas for both indices was 0.49. As such, differences that existed among the study areas were as much the result of differences in actual species composition as differences in the abundances of species shared in common. Species diversity indices ranged from 1.40 (Bald Knob) to 2.31 (Beanfield Mountain). Values for the other study areas were 2.14 (Spruce Bog), 1.76 (War Spur) and 1.72 (Pond Drain). 
Table 2 Numbers of records of myxomycetes obtained for each of the study areas.

\begin{tabular}{|c|c|c|c|c|c|c|}
\hline Species & $\begin{array}{l}\text { Beanfield } \\
\text { Mountain }\end{array}$ & $\begin{array}{c}\text { Spruce } \\
\text { Bog }\end{array}$ & $\begin{array}{l}\text { War } \\
\text { Spur }\end{array}$ & $\begin{array}{l}\text { Pond } \\
\text { Drain }\end{array}$ & $\begin{array}{l}\text { Bald } \\
\text { Knob }\end{array}$ & Total \\
\hline Arcyria cinerea & 9 & 11 & 11 & 11 & 10 & 52 \\
\hline Perichaena chrysosperma & 8 & 1 & 1 & 8 & & 18 \\
\hline Comatricha nigra & 1 & 5 & 7 & 2 & & 15 \\
\hline Physarum viride & 1 & 4 & 2 & 2 & & 9 \\
\hline Licea operculata & 2 & 2 & & 1 & 2 & 7 \\
\hline Stemonitis flavogenita & 4 & & 1 & & 1 & 6 \\
\hline Diderma effusum & 2 & 2 & 1 & & & 5 \\
\hline Echinostelium minutum & 1 & 3 & & & 1 & 5 \\
\hline Physarum oblatum & 3 & 2 & & & & 5 \\
\hline Stemonitis nigrescens & 1 & 2 & 1 & & 1 & 5 \\
\hline Cribraria microcarpa & & 4 & & & & 4 \\
\hline Physarum galbeum & & & 1 & 2 & & 3 \\
\hline Trichia munda & & & & 3 & & 3 \\
\hline Arcyria denudata & & 1 & 1 & & & 2 \\
\hline Arcyria cf. pomiformis & 1 & & & & & 1 \\
\hline Comatricha sp. & & & 1 & & & 1 \\
\hline Licea belmontiana & 1 & & & & & 1 \\
\hline Physarum bivalve & & & & & 1 & 1 \\
\hline Physarum crateriforme & & & & 1 & & 1 \\
\hline Physarum lateritium & & & & & 1 & 1 \\
\hline Physarum cf. pusillum & 1 & & & & & 1 \\
\hline Physarum sp. A & 1 & & & & & 1 \\
\hline Physarum sp. B & 1 & & & & & 1 \\
\hline Total & 37 & 37 & 27 & 30 & 17 & 148 \\
\hline
\end{tabular}

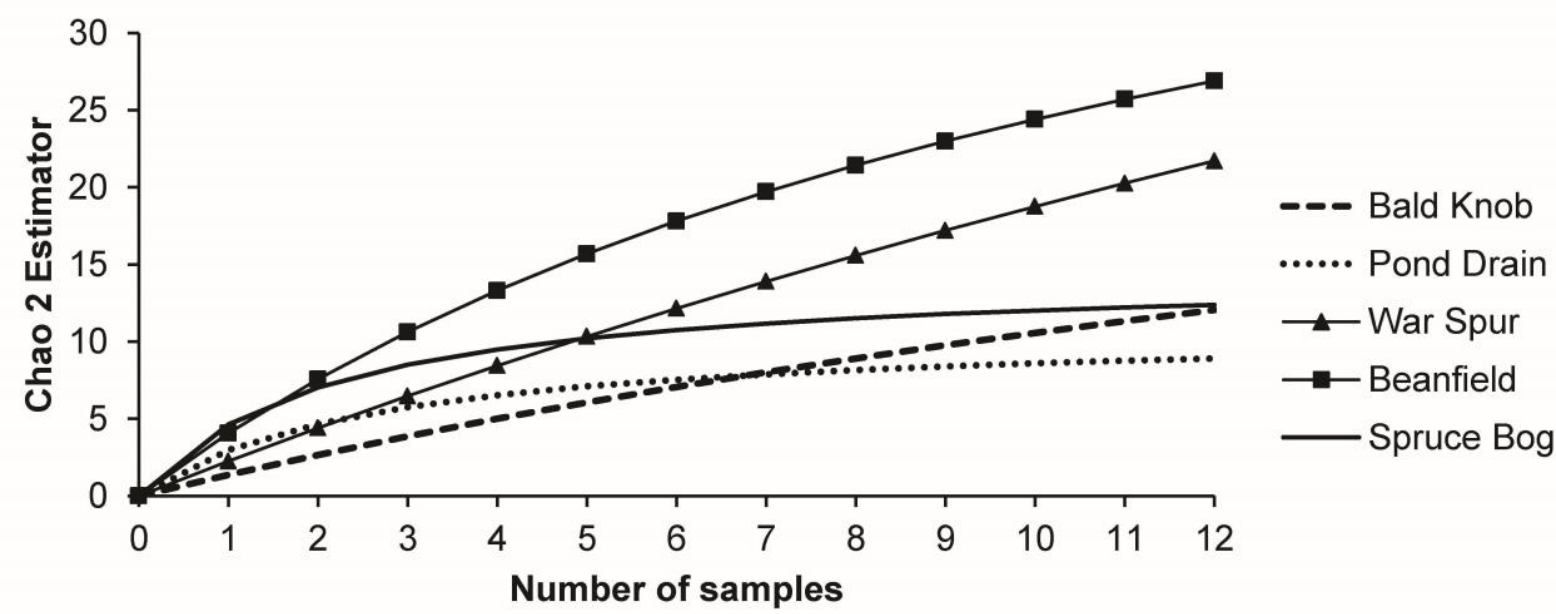

Fig. 2 - Chao 2-based rarefaction curves generated for the five study areas.

Species accumulation curves generated using the Chao 2 estimator (Fig. 2) indicate that sampling in the five study areas was not complete (i.e., not all of the species present were collected), but the slopes of the curves also indicate that the collecting effort and number of samples used yielded an appreciable percentage of the species likely to be encountered. For two of the study areas (Pond Drain and Spruce Bog) the curves leveled out to such an extent that the most of the species present are likely to have recorded. 
Table 3 Comparison of study areas using coefficient of community (upper right) and percentage similarity (lower left) indices.

\begin{tabular}{lccccc}
\hline Study area & $\begin{array}{c}\text { Beanfield } \\
\text { Mountain }\end{array}$ & $\begin{array}{c}\text { Spruce } \\
\text { Bog }\end{array}$ & $\begin{array}{c}\text { War } \\
\text { Spur }\end{array}$ & $\begin{array}{c}\text { Pond } \\
\text { Drain }\end{array}$ & $\begin{array}{c}\text { Bald } \\
\text { Knob }\end{array}$ \\
\hline Beanfield Mountain & $* * *$ & 0.69 & 0.56 & 0.43 & 0.45 \\
Spruce Bog & 0.54 & $* * *$ & 0.67 & 0.53 & 0.44 \\
War Spur & 0.44 & 0.63 & $* * *$ & 0.56 & 0.35 \\
Pond Drain & 0.55 & 0.49 & 0.58 & $* * *$ & 0.27 \\
Bald Knob & 0.41 & 0.46 & 0.48 & 0.40 & $* * *$ \\
\hline
\end{tabular}

\section{Discussion}

In the earlier study of the litter microhabitat (Stephenson 1989), 34 species in 16 genera were recorded. However, the number of moist chamber cultures prepared for each study area was higher than in the present study, and samples were collected on more than a single occasion (all twigs were collected over a two-day period in the present study). Because these earlier samples also would have been more heterogeneous (i.e., consisting both leaves and some non-leaf material), a higher level of diversity might have been expected. As already noted, $98 \%$ of the moist chamber cultures prepared with twigs in the present study yielded myxomycetes. This figure is higher than the mean value (75\%) reported for litter in the earlier study. Stephenson et al. (2008) reported an average value of $67 \%$ positive cultures for sets of twigs from a series of localities in different regions of the world. However, this value reflects the fact that the productivity of a few sets of samples (e.g., tropical forests of Costa Rica) were appreciably lower $(\leq 43 \%)$. Sets of samples collected from broadleaf temperate forests (e.g., Virginia and Arkansas in the United States) were generally much higher (100\% in one instance). A consideration of all of these data clearly indicates that twigs represent a productive microhabitat for myxomycetes in the habitats that have been examined thus far.

Arcyria cinerea, the most common species recorded in the present study, also was abundant on litter in the earlier study, where it appeared in $43 \%$ of all cultures. Moreover, in both studies, the numbers of records of $A$. cinerea for the five different study areas were fairly comparable. This suggests that both litter and twigs represent more or less equally favorable microhabitats for $A$. cinerea, which is recognized as one of the more abundant and widespread myxomycetes worldwide, where it occurs in virtually all of the different types of microhabitats known to support the growth and development of this group of organisms (Stephenson \& Stempen 1994).

As a general observation, with the noteworthy exception of A. cinerea, the species of myxomycetes recorded from litter by Stephenson (1989) tended to be much less common or even completely absent from twigs. Only 11 of the 23 species appearing on twigs in the present study also were recorded on litter in the earlier study. Moreover, species such as Perichaena chrysosperma, Comatricha nigra and Licea operculata (each recorded in $>10 \%$ of all cultures) were appreciably more abundant on twigs than on litter.

In the earlier study, the correlations between myxomycete diversity in the litter microhabitat and various measures computed or determined for the five study areas were examined, and the strongest correlation was found to exist with the species richness of woody stems. For example, samples of litter collected in the Beanfield Mountain study area, which was characterized by the highest species richness of woody plants (29 species), yielded the highest number of species of myxomycetes (19), whereas just 11 species were recorded from Pond Drain, with only 15 species of woody plants present. Since woody plants represent the major source of the primary resource (i.e., dead leaves) utilized by litter-inhabiting myxomycetes, such a pattern would suggest that a 
higher diversity in the woody plants present at a particular locality is reflected in a higher diversity in the assemblage of myxomycetes. However, the data available for this aspect of myxomycete ecology is still rather limited.

Interestingly, twigs collected in the Beanfield Mountain study area in the present study also produced the highest number of species of myxomycetes (15). The lowest number of species (7) was recorded for Bald Knob, in which species richness of woody plants was appreciably lower (19 species.) However, the latter figure, which includes all woody plants (including species of shrubs) undoubtedly understates the species richness of the tree stratum, where red oak was an overwhelming dominant. Presumably, most of the twigs collected in this study area were derived from red oak. The same situation existed for Pond Drain, where most of the trees present were beech, and this study site was characterized by the second lowest total (8) for myxomycetes recorded from twigs. As such, the data generated for the twig microhabitat appear to follow the same basic pattern reported for the litter microhabitat in the earlier study.

In most instances, the values of $\mathrm{pH}$ recorded for litter and twigs were fairly comparable. The mean value for all cultures prepared with litter in the earlier study was 5.2 (range of 3.6 to 6.5), which is only slightly higher that the corresponding value (4.9) for twigs. Litter samples from Pond Drain were the least acidic (mean $\mathrm{pH}=5.5$ ) and those from War Spur (4.6) and Spruce Bog (4.7) the most acidic. Cultures prepared with twigs from War Spur $(\mathrm{pH}=4.6)$ and Spruce Bog $(\mathrm{pH}=4.2)$ also were the most acidic, but those collected from Beanfield Mountain (mean $\mathrm{pH}=6.3$ ) were the least acidic. The fact that cultures prepared with twigs from Beanfield Mountain yielded the highest number of species and shared the highest number of records with Spruce Bog would seem noteworthy. It is generally known that that some species of myxomycetes do not appear to tolerate conditions of low pH (Stephenson \& Stempen 1994), so twigs characterized by a relatively higher $\mathrm{pH}$ would seem likely to support a more diverse assemblage of species.

In summary, although there is considerable overlap in the taxonomic composition of the species of myxomycetes associated with the litter and twig microhabitats, there are some species that appear to be restricted largely to one microhabitat or the other. Moreover, twigs from different types of woody plants support somewhat different assemblages of myxomycetes, although a few species such as Arcyria cinerea tend to be consistently present. As such, there would seem to be some justification for including woody twigs in any comprehensive survey for myxomycetes at a given locality.

\section{Acknowledgements}

Appreciation is extended to Dr. Carlos Rojas for his assistance in preparing Figure 2.

\section{References}

Braun EL. 1950 - Deciduous Forests of Eastern North America. The Blakiston Company, Philadelphia, Pennsylvania.

Gauch HG Jr. 1982 - Multivariate Analysis in Community Ecology. Cambridge University Press, Cambridge, United Kingdom.

Gilbert HC, Martin GW. 1933 - Myxomycetes found on the bark of living trees. University of Iowa Studies in Natural History 15, 3-8.

Härkönen M. 1981 - Myxomycetes developed on litter of common Finnish trees in moist chamber cultures. Nordic Journal of Botany 1, 791-794.

Lado C. 2005-2014 - An online nomenclatural information system of Eumycetozoa. http://www.nomen.eumycetozoa.com (accessed on 15 July 2014).

Martin GW, Alexopoulos CJ. 1969 - The Myxomycetes. University of Iowa Press, Iowa City.

Mueller-Dombois D, Ellenberg H. 1974 - Aims and Methods of Vegetation Ecology. John Wiley and Sons, New York.

Raaijmakers JGW. 1987 - Statistical analysis of the Michaelis-Menten equation. Biometrics 43, 793-803. 
Rollins AW, Stephenson SL. 2012 - Myxogastrid distribution within the leaf litter microhabitat. Mycosphere 3, 543-549.

Shannon CE, Weaver W. 1963 - The Mathematical Theory of Communication. University of Illinois Press, Irbana, Illinois.

Stephenson SL. 1986 - Changes in a former chestnut-dominated forest after a half century of succession. American Midland Naturalist 116, 173-179.

Stephenson SL. 1988 - Distribution and ecology of myxomycetes in temperate forests. I. Patterns of occurrence in the upland forests of southwestern Virginia. Canadian Journal of Botany 66, 2187-2207.

Stephenson SL. 1989 - Distribution and ecology of myxomycetes in temperate forests. II. Patterns of occurrence on bark surface of living trees, leaf litter, and dung. Mycologia 81, 608-621.

Stephenson SL. 2011 - From morphological to molecular: studies of myxomycetes since the publication of the Martin and Alexopoulos (1969) monograph. Fungal Diversity 50, 21-34.

Stephenson SL, Stempen H. 1994 - Myxomycetes: A Handbook of Slime Molds. Timber Press, Portland, Oregon.

Stephenson SL, Urban LA, Rojas C, McDonald MS. 2008 - Myxomycetes associated with woody twigs. Revista Mexicana de Micologia 27, 21-28.

Tran HTM, Stephenson SL, Hyde KD, Mongkolporn O. 2008 - Distribution and occurrence of myxomycetes on agricultural ground litter and forest floor litter in Thailand. Mycologia 100, 181-190.

Unterseher MM, Schnittler M, Dormann C, Sickert A. 2008 - Application of species richness estimators for the assessment of fungal diversity. FEMS Microbiology Letters 282, 205213. 